\title{
EL "DESCUBRIMIENTO MODERNO DE LA ORALIDAD" Y LOS MEDIOS AUDIOVISUALES
}

\author{
Mateu Cabot
}

Eric Havelock, en su libro La musa aprende a escribir (1986), acuñó la expresión "descubrimiento moderno de la oralidad". Con ella quería referirse a la toma de conciencia de la importancia del medio en los procesos de constitución y transformación de una cultura. Más en concreto, sobre la importancia determinante que había tenido la escritura en la formación de la cultura moderna.

La transmisión de la experiencia de generación en generación se realizó oralmente de forma exclusiva hasta el cuarto milenio a. C. En la edad del hierro en Egipto, Mesopotamia y China se inventan un código gráfico que sea, a la vez, suficientemente potente para reforzar la memoria colectiva con signos pintados, inscritos o grabados, sistemas de signos que sirvan para codificar información cada vez más compleja y que sean lo suficientemente flexibles para facilitar su aprendizaje y adaptarse a las situaciones concretas cambiantes.

La escritura es el producto más eficientedeestetipo. En las tradiciones orales, no alfabetizadas, aquellos contenidos que constituyen las normas más generales de una comunidad determinada, su Weltanschaung, se asegura su transmisión de generación en generación mediante acciones con una estructura repetitiva del mismo contenido y con una modulación fonética fácilmente asimilable y memorizable, principalmente por basarse en ritmos simples. Encontramos ecos de estas técnicas en los ritmos del folclore, en la estructura repetitiva y cicla de las mitologías y en otros materiales que forman aquella cosmovisión aludida. En todos 
ellos se trata de reducir la complejidad de lo transmitido, refiriéndolo a patrones sonoros y/o métricos rápidamente asimilables a los que se encuentran en el entorno natural y/o social en el que aparece el mensaje. La escritura es el sistema de conservación y de transmisión del saber colectivo más eficiente, de forma definitiva a partir de la escritura alfabética alcanzada en Grecia, pues permite ampliar enormemente la capacidad comunicativa respecto a los niveles alcanzados exclusivamente con la comunicación oral.

\section{EL LLAMADO “DESCUBRIMIENTO MODERNO DE LA ORALIDAD”}

Havelock (1986/1996, p. 47) se refiere específicamente al momento, alrededor de 1963, en que aparecen varios textos ${ }^{1}$ que, desde diferentes campos, analizan el mecanismo de transformación de la cultura, entendida ésta como mecanismo de acumulación de conocimiento socialmente necesario. Uno de esos mecanismos, tal vez el definitorio de nuestra cultura, es la escritura. Para dar cuenta de las transformaciones debidas a la alfabetización, se supone un estado de oralidad primigenia, previa a la invención de la escritura, estado en el que los mensajes, las ideas, las opiniones y las emociones, etc. solo se materializaban en voces, palabras. La intención no es, sin embargo, investigar ese estado primitivo, sino los cambios que provocó, en dicho estado de oralidad, la introducción de la escritura; la adopción de la escritura como el medio prioritario para guardar y transmitir el acervo cultural de la especie, representa algo así como la toma de conciencia de que el escribir no es lo mismo que el contar de viva voz.

Hasta aproximadamente el año 70oa. C., no hay un sistema deescritura que se utilice más allá del restringido círculo de las castas dominantes, únicas que utilizaban los signos con funciones, fundamentalmente, de administrar el patrimonio cultural y, sobre todo, el poder de los gobernantes. La primera constancia clara de uso generalizado y no restringido a castas de la escritura se produce sólo en los siglos VI-V a. C. en la Jonia griega; en aquél momento se dan dos factores que, unidos, posibilitarán el definitivo avance de un código escrito: por una parte las características de las sociedades necesitadas de una comunicación permanente y, por otra parte, la transformación de sistemas de grafía anteriores para crear el primer alfabeto efectivo y progresivo, el griego.

${ }^{1}$ Las cinco obras son: El pensamiento salvaje (1962) de Claude Lévi-Strauss, La galaxia Gutenberg (1962) de Marshall McLuhan, Especies animales y evolución (1963) de Ernst Mayr, el artículo "The consequences of literacy” (1963) de Jack Goody e Ian Watt y, por último, Prefacio a Platón (1963) del propio Eric A. Havelock. 
Las características propias del alfabeto griego, aunque técnicamente superiores frente a otros tipo de escritura, no explicarían por si solos la explosión literaria que se produce a partir del siglo VII-VI a. C. Hasta aquel momento la escritura había estado unida a la exigua (numéricamente) clase dominante, a los códigos de la corte, de la administración de la riqueza y del control ideológico-religioso de la sociedad. Los escribas aparecen en Egipto como funcionarios del Faraón, administradores de sus riquezas y controladores del culto. En la Biblia aparecen como casta conservadora y subalterna al poder de los reyes. En cualquier caso el saber descifrar el código, saber leer y escribir, era uno de los atributos del poder. En el nuevo testamento el nombre del que sabe leer y escribir aún va ligado a esas funciones gobernantes y lleva la connotación de "burócrata" que, con unos signos desconocidos (y prohibidos en ocasiones) para el resto de mortales, mantiene alejado el poder. Sin embargo, la nula utilidad en la práctica cotidiana que tenía el saber leer y escribir en las sociedades teocráticas y, sobre todo, altamente centralizadas de Oriente Medio es considerada como la causa principal de la tardía popularización de la escritura. Entre los pueblos marítimos griegos, la necesidad de intercambio con los pueblos vecinos, también alfabetizados, impulsa la escritura como ayuda del comercio y de las actividades económicas. La escritura sólo es posible cuando aquello que debe escribirse y leerse se democratiza, tal como sucede en pequeñas ciudades marítimas dedicadas al comercio para subsistir. En este contexto crece exponencialmente el número de individuos que saben leer, a pesar de que la técnica de la escritura aún debía mejorarse hasta llegar a la actual (GOODY e WATT, 1963, p. 68). La lectura tiene un sentido público y los libros, difíciles de conseguir, se leen en voz alta. La comunicación oral y la escrita mediante el alfabeto tienen características claramente diferentes en cuanto a su conservación y permanencia. La larga historia hasta llegar al papel actual resume la historia de la tecnología de conservación de los registros escritos, aunque la permanencia o la facilidad de conservar aquello codificado no es el único cambio, evolutivamente progresivo, que introduce la escritura.

\section{LA ESTRUCTURA DE LA ESCRITURA}

Para el historiador de la escritura Ignace Gelb no hay ninguna duda: "Si se define el alfabeto como un sistema de signos que expresan sonidos individuales del habla, entonces el primer alfabeto que merece justificadamente tal nombre es el alfabeto griego" (GELB, 1952/1991, p. 217). Goody y Watt analizaron la superioridad del alfabeto griego sobre las otras escrituras utilizadas hasta el momento. El paso fundamental se da cuando los signos representan fonemas y no objetos o acciones: 
The notion of representing a sound by a graphic symbol is itself so setupefyng a leap of the imagination that what is remarkable is not so much that it happened relatively late in human history, but rather that it ever happened at all (GOODY e WYATT, 1963, p. 38).

El alfabeto griego evoluciona los sistemas gráficos semitas diferenciando entre vocales y consonantes, consiguiendo de esta manera representar, con un número reducido de signos, en torno a 27 , la totalidad de sonidos significativos en la lengua con un bajo nivel de ambigüedad. El alfabeto griego fue la transformación definitiva de los alfabetos de lenguas semíticas, que ya habían establecido las letras como representación de sílabas pero sin vocales. El griego añadió las vocales y terminó con ello con una parte importante de la ambigüedad de las anteriores escrituras, tanto que ya había dado lugar a un saber especializado en la interpretación de esa ambigüedad: la hermenéutica tuvo su origen en los ilimitados sentidos de los libros sagrados del Antiguo Testamento. Un ejemplo históricamente relevante se encuentra en Reyes 1, 17, 5-7:

\footnotetext{
Elías hizo lo que le mandó el Señor y fue a vivir junto al torrente Carit, que queda cerca del Jordán. Los cuervos ${ }^{2}$ le llevaban pan por la mañana y carne por la tarde, y bebía del torrente (ed. Nueva Biblia Española, p. 490).
}

Las posibilidades de emitir sonidos del aparato fonador humano son muy amplias, pero la fonología ha inventariado sólo unos cuarenta fonemas en todas las lenguas habladas en el mundo. El alfabeto ingles moderno se compone de 28 letras con las que se representan los 44 fonemas del idioma, uno de los más amplios fonéticamente. Incluso más que la reducción del sentido denotativo a connotativo, otra característica del alfabeto griego resulta una ventaja evolutiva clara: su aprendizaje requiere menos tiempo de dedicación. Platón, en Leyes (810a), establece que los niños dedicarán 3 años al aprendizaje de la lectura y la escritura, un tiempo de dedicación sostenible por la mayoría de sociedades. Por el contrario, para alcanzar el mismo grado de competencia en la escritura china se precisan dominar 3.00o caracteres, aunque ello resulta ínfimo comparado con el tiempo de dedicación para alcanzar la maestría con esta grafía. Los 50.000 caracteres que debe dominar un maestro precisan un mínimo de 20 años de estudio.

En Platón encontramos un documento del choque de la emergente cultura escrita con la aún mayoritaria oralidad. En el diálogo Hipias mayor y a propósito de la idea de "belleza". Platón escribe una conversación entre Sócrates e Hipias, que podría resumirse diciendo que Hipias le cuenta a

El signo para "cuervo" puede leerse, también, como "árabe”. 
Sócrates lo que es bello y este último le pregunta que es bello. Sócrates pregunta por la definición, por la esencia de la palabra "belleza", kalos, de lo que va unido a los trazos del alfabeto griego, e Hipias describe los momentos de la experiencia en los que se experimenta "algo" a lo cual todos los hablantes llaman "belleza". Evidentemente Platón presenta la postura socrática como superior pues no depende de un número indeterminado de sucesos y eventos distintos en el espacio y el tiempo. También porque simplifica el mensaje reduciéndolo lo más posible a su dimensión cognitiva, dejando fuera la afectiva o emocional. Un proceso más de abstracción, necesario para el progreso.

La Ilustración europea en el siglo XVIII consolidó procesos de formalización largamente preparados: la alfabetización generalizada que se inició entonces con el objetivo principal de "ilustración" conllevó otros procesos de formalización y, en la dimensión social, de redefinición de los criterios de validez. La teoría política del liberalismo y de la división de poderes es una muestra más de la necesaria formalización y clarificación cognitiva de los diferentes ámbitos de la vida de la especie. Kant representa de la forma más elocuente este proceso que puede llamarse, simplemente, de modernización. Como aclara explícitamente en Crítica del juicio (1790), el juicio lógico (cognitivo) no es un juicio moral ni estético; toda su obra avanza realizando distinciones dónde antes sólo existía confusión de elementos diversos: de igual modo que Ferdinand Tönnies explicó diferenciando entre una "comunidad" (Gemeinshaft) y una "sociedad" (Gesellschaft) según la naturalidad o formalidad de los vínculos entre los individuos participantes, las relaciones cognitivas del individuo con su entorno pueden adoptar diversos grados de formalidad. La ciencia natural seria un ejemplo de máxima formalización en la relación del individuo con la naturaleza, el animismo sería un ejemplo de formalización mínima o nula. Es en este sentido que puede afirmarse que el lenguaje escrito posee un nivel de formalidad (o abstracción) mayor que el lenguaje oral.

\section{LA EMERGENCIA DE LA CULTURA AUDIOVISUAL}

El momento en que se "descubre" una oralidad primitiva, esto es, que somos una cultura escrita, es precisamente en el que aparece en escena una cultura que no utiliza la escritura para conservar y difundir los contenidos. En la década de 196o la bonanza económica de la posguerra ha producido un extenso mercado de aparatos de televisión, teléfonos y reproductores de discos de vinilo que ya no puede ser considerada por más tiempo como una sub-cultura, como si de una pequeña anomalía de la cultura principal, la escrita, se tratara. 
Desde finales del siglo XIX el ámbito de la cultura participa activamente en las transformaciones sociales, económicas e incluso psicológicas habidas, bien sea reflejándolas, sensibilizando así el espíritu del tiempo, bien sea yendo por delante de las conciencias individuales, a modo de "espíritu objetivo". Algunas aplicaciones técnicas introducidas en el ámbito cultural, como el cine, provocan inmediatamente cambios culturales, económicos, sociales y psicológicos que ensanchan el propio campo de la cultura, ampliando los horizontes hasta el infinito (al menos eso parece). El apellido "de masas" del término "cultura de masas", habitual a partir de mitad del siglo XX, se refiere no al agente productor de la "cultura" (como si la cultura fuera producida por "las masas"), sino al destinatario de la cultura, producida técnicamente (como garantía de su posibilidad de producción en serie) y necesariamente estandarizada.

Con esta intención son especialmente significativos dos rasgos de la cultura de masas: (1) su estrecha conexión con innovaciones técnicas concretas, cada vez más cercanas (incluso físicamente) a la "conciencia" del sujeto (la intimidad, la "mismidad"), y (2) su éxito como forma de cultura y como industria cultural. A principios del siglo XXI incorpora prácticamente a la totalidad de los individuos del planeta, uno de los aspectos de la globalización. Es la primera vez en la historia que hay una cultura común, en su totalidad o en partes significativas, en todo el planeta; $y$ sin tener que mantener, además, dos subsistemas (high and low culture). Parte de ese éxito reside en que la propia cultura se encarga explícitamente de expandir el modelo: será el llamado modelo del american way of Life. La existencia de un vasto mercado unificado ha propiciado que, por primera vez en la historia de las culturas alfabéticas, la low culture sobrepasara a la high culture y se convirtiera en hegemónica, obligando así a la transformación de lo que hasta el momento había sido high culture (CABOT, 2007).

La creación de un mercado de productos de consumo, tal como preconizaba el keynesianismo como forma para hacer duradero el capitalismo, explica el consumo de los aparatos e incluso de los productos audiovisuales, pero no su éxito, el hecho de que se consuman con fruición y que sean objeto del deseo. El origen de ese poder de penetración y modulación de la subjetividad humana la señaló Walter Benjamin en los primeros momentos de la nueva cultura. En el párrafo 11 dice:

El rodaje de una película, y en especial de una película sonora, nos ofrece un aspecto nunca ni en ninguna parte hubiera resultado concebible. Representa un proceso al que no le cabe ya asignar un punto de vista desde el que los aparatos de filmación no pertenecientes al proceso filmado, la maquinaria de iluminación, el equipo de ayudantes, etc., no entren en el campo visual del espectador (BENJAMIN, GS, I, p. 495). 
El mecanismo se traslada a los órganos sensoriales humanos; se ve lo que aparece en la pantalla, se oye lo que suena ante las imágenes de la pantalla. El cine consigue reproducir lo visto y lo oído, e igual que conservamos un rostro en una fotografía, conservamos de esta forma nuestras percepciones, de otra forma efímeras.

El cine, entendido como reproducción de imágenes y sonidos en movimiento, necesita de diferentes tecnologías para su funcionamiento y estas forman parte del entramado económico de las sociedades contemporáneas. Las imágenes y sonidos que son producidos y reproducidos en los diferentes ámbitos de la vida social responden a la necesidad del mercado de deseos y a la ventaja técnica del cine, tal como comentaba Benjamin.

El uso intensivo de tecnología para crear los objetos culturales y la producción masiva era ya la forma dominante en Estados Unidos desde la década de 1930 y se extenderá por Europa en el largo período de crecimiento económico después de 1945. Los aspectos de ruptura con respecto al pasado que representa esta nueva configuración de la cultura fueron detectados ya por Walter Benjamin desde mediados de los años 30. Benjamin analizó los nuevos medios técnicos (fotografía, cine, prensa) no sólo considerando las transformaciones que estos medios realizaban sobre el material con que trabajaban (en la mayoría de ocasiones el mismo sobre el que trabajaban medios tradicionales, como la pintura o la literatura), sino principalmente por los nuevos efectos o transformaciones que producían sobre los individuos que los utilizaban para crear o consumir dichos objetos. A la primera perspectiva dedica "La obra de arte en la época de su reproducibilidad técnica" (1935), a la segunda "Experiencia y pobreza" (1933) o el inacabado Libro de los Pasajes.

Respecto al primer rasgo citado nos interesa tratar una de las últimas innovaciones técnicas con fuertes consecuencias en la cultura: la "audiovisualidad", las tecnologías que han permitido registrar, conservar, transmitir, modificar, etc. imágenes y sonidos que nosotros entendemos y que constituyen los elementos básicos de nuestra cultura. Esto es, tecnologías de la imagen y del sonido, en el campo de la producción de imágenes y sonidos, su transmisión y su recepción, en cualquier soporte material en el que se plasmen las imágenes y los sonidos y en cualquier medio para su producción/transmisión/recepción. Esta innovación va evidentemente ligada a la "digitalidad", en el sentido de la conversión de todos los signos en únicamente dos, pero es diferente. La posibilidad de reducir toda imagen y sonido a código binario es un avance más en la línea de la invención del telégrafo por parte de Samuel Morse en 1834. Si los griegos habían conseguido un código de 26 signos (aproximadamente) 
para fijar y transmitir nuestros pensamientos, Morse redujo estos 26 a 3 (punto, raya, pausa), y reglas simples para poder traducir el código escrito en alfabeto latino a un código fácilmente transmisible por impulsos eléctricos. La tecnología digital reduce los signos a 2: on y off, con la ayuda del pulso del reloj de la CPU. Sólo se trataría de una mejora cuantitativa, de eficiencia energética. La diferencia estriba en que el telegrama transmitido en código morse se retraducía y se leía, y la tecnología digital ha ampliado universalmente las imágenes y los sonidos, más que los textos escritos.

Aún está por investigar el alcance de estas transformaciones. Nos interesa especialmente aquí una de ellas, precisamente la que va en dirección contraria a la que propició la Ilustración con el fomento de la alfabetización universal: autonomizar los distintos discursos y establecer criterios específicos para cada uno de ellos. La escritura no sólo posibilitaba registrar, reproduciry transmitir el discurso que anteriormente, en tiempos en que sólo existía la comunicación oral, sólo podía repetirse. Junto a estas posibilidades técnicas, pues era gracias a la escritura y a la imprenta que existían, venían unidas a ellas unas condiciones de utilización. Esas condiciones portaban en sí unos criterios de funcionamiento y, por tanto, validez. La comunicación oral estaba unida a una proximidad física y social que no podía formalizarse, estará siempre unida a rasgos emotivos, contextuales, sub-texto etc. La comunicación audiovisual parece mostrar la misma inmediatez de la comunicación oral, aunque diste mucho de ser el caso. Los medios para comunicar ideas no son infinitos sino bien limitados (GELB, 1952/1991, p. 26), los problemas - sociales - aparecen cuando los recursos tecnológicos se descompasan de los modos sociales de comprensión; cuando, por ejemplo, medios técnicos que requieren una alta formalización permiten modos sociales de comprensión pre-formalizados (como la comunicación oral) y ello, además, facilita el dominio ideológico y político de los poseedores de los recursos tecnológicos.

\section{CARACTERÍSTICAS DEL CÓDIGO AUDIOVISUAL}

Aunque se trate sólo del registro literal del discurso hablado, la escritura conserva el significado del discurso, añadiendo a lo sumo indicaciones acerca de la modalidad del mismo: tenemos en el guión cinematográfico un ejemplo de esto, del discurso escrito se tiende ahorrar toda indicación que no sea estrictamente transmisión de información abstracta. En general toda la expresividad de la oralidad queda eliminada en la escritura. Esta expresividad, junto con la repetición y la sonoridad de las mismas, era uno de los elementos que ayudaban a la conservación (memorizada) del discurso oral, necesidad que con la escritura alfabética desaparece. 
El aprendizaje del código escrito representa también características diferenciadas. El esfuerzo para su aprendizaje no proviene de la necesidad de aumentar la capacidad memorística y de su recuperación, sino en la adquisición de las reglas de formación del mensaje. Una vez aprendidas estas reglas, por lo general reglas bastante simples, la iteración sucesiva de las mismas permite la codificación de cualquier mensaje. No son estrictamente necesarios el apoyo de determinados ritmos que ayudan en la memorización de mensajes orales significativamente extensos o difíciles por cualquier causa. El código queda así liberado de prácticamente cualquier carga que no sea la cognoscitiva conducida por el propio mensaje. Aprender la escritura (y la lectura) es acceder al saber colectivo, formando parte la adquisición de la escritura de los mecanismos socializadores de los individuos.

La estructura secuencial del código escrito, la escritura, posibilita la generación potencial de infinitos mensajes. Esta posibilidad ha sido motivo incluso de recreaciones literarias. En un plano analítico, la linealidad que introduce la escritura se diferencia del carácter más holístico de la comunicación oral. Igual que la visión, el mensaje oral funciona como un todo, algo que debe captarse en su totalidad, integrando en esa totalidad los elementos que pudieran diferenciarse en un análisis posterior del mismo mensaje. Igual que la visión la comunicación oral se produce integrada en un determinado contexto vital. Resulta, por ello, difícilmente abstraíble de las circunstancias concretas, tanto espaciales como temporales y sociales en general, en que tiene lugar. Del mismo modo que la psicología de la percepción puso de manifiesto desde principios del siglo XX los preconceptos que estructuraban la visión (WERTHEIMER, 1924/1985), en la comunicación oral el hablante parte, además de toda la estructura del lenguaje nativo, de una tradición en la que adquieren significado y sentido los mensajes además de usos idiosincrásicos del hablar.

La escritura puede alcanzar una abstracción no posible con la oralidad, siempre narrando un "hacer". El nivel de abstracción de los conceptos generales se alcanza progresivamente. La historia de la filosofía occidental, desde sus orígenes en la Jonia griega, es una muestra de esta progresiva adquisición de conceptos abstractos cada vez más elaborados. En este sentido puede leerse el esfuerzo de los llamados filósofos presocráticos investigando el $\alpha ́ \rho \chi \varepsilon ́$, esto es: aquello que es el origen y fuente viva de todo lo existente. Tal nivel de abstracción, nivel definido por su alejamiento del mundo de vida cotidiana, sólo es posible fijando en palabras el sentido que se va acumulando, fijación que resulta difícilmente imaginable sin el auxilio de la escritura. Estos conceptos abstractos necesitan ser explicados a través del discurso escrito para que adquieran realidad. Los fragmentos 
que nos han llegado desde las distintas ciudades helénicas desde el siglo VIII al IV a. C. muestran los variados intentos de significar esos conceptos, esfuerzos que culminaran en los textos de Aristóteles, en el siglo IV a. C., con la creación sistemática de una terminología metafísica, esto es: palabras para designar aquello que está más allá de lo físico y, a la vez, sustentándolo.

Desde diversas perspectivas se ha subrayado que la escritura alfabética favorece las capacidades abstractivas, que a su vez son más eficientes evolutivamente a partir de un determinado grado de complejidad social. Las tesis evolucionistas de Mayr ya reseñadas insisten en la necesidad del aprendizaje social acumulable que, a su vez, interactúa con los mecanismos de adaptación biológica al medio ambiente. Los conocimientos de la psicología cognitiva, con Jean Piaget al frente, han detallado los mecanismos de desarrollo cognitivo en los individuos y su conexión con los grados de evolución social. En esta tendencia el grado superior de desarrollo de las capacidades cognitivas se denomina "etapa de operaciones formales", caracterizándose por la adquisición de un nivel de abstracción que permite un aprendizaje no limitado al entorno inmediato. El mismo mecanismo fue descrito por Kohlberg (1992) por lo que hace al desarrollo de estructuras morales abstractas que definan y signifiquen la posición del individuo dentro de su contexto social. Al margen de la controversia teórica que esta última teoría ha suscitado, es de notar las consecuencias evolutivas que marcan cada uno de los estadios de desarrollo tanto de la inteligencia abstracta como del razonamiento moral formalizado y universalista.

\section{CONCLUSIÓN}

Si la imprenta fue el principio del fin de la oralidad como forma hegemónica y su sustitución por la escritura alfabética, las tecnologías audiovisuales (aprovechando el canal eficiente que permite la digitalidad) significan la saturación de la cultura escrita con imágenes y sonidos que no sólo amplían el horizonte de la lectura/escritura, sino que los modifican en aspectos nuevos, no conocidos. Suponiendo esta analogía, los estudios sobre el significado de la alfabetización universal iniciada en el siglo XV pueden orientar en el análisis de la cultura de masas si se la considera un resultado de la "audiovisualización" realizada intensivamente a partir de mitad del siglo XX. 


\section{Cabot - 175 \\ REFERÊNCIAS BIBLIOGRÁFICAS}

BENJAMIN, W. Experiencia y pobreza. [1933]. In: GS. V. II/1. Frankfurt: Suhrkamp, 1991. p. 213-219.

BENJAMIN, W. El narrador. [1936]. In: GS. V. II/1. Frankfurt: Suhrkamp, 1991. p. 438-465.

BENJAMIN, W. La obra de arte en la época de su reproducibilidad técnica. [1939]. In: GS. V. I/2, Frankfurt: Suhrkamp, 1991. p . 471- 508.

BENJAMIN, W. Libro de los pasajes. [1982]. In: GS. V. Frankfurt: Suhrkamp, 1991.

CABOT, M. Más que palabras. Estética en tiempos de cultura audiovisual. Murcia: Cendeac, 2007.

CABOT, M. Sobre los medios técnicos y la renovación de tradiciones. Walter Benjamin y el concepto de 'experiencia' pensado desde la estética. In: AMENGUAL, G.; CABOT, M.; VERMAL, J.L. (Eds.). Ruptura de la tradición. Estudios sobre Walter Benjamin y Martin Heidegger. Madrid: Trotta, 2008. p. 61-82.

CABOT, M. La estética es ya sociología. La dimensión sociológica de la teoría estética de Th. W. Adorno. Arxius de Ciències Socials, 22, p. 37-46, Valencia, 2010.

GELB, I. J. Historia de la escritura. [1952]. Trad. Alberto Adell. 4ª reimpresión. Madrid: Alianza Editorial, 1991.

GOODY, J.; WATT, I. The consequences of literacy. Comparative Studies in Society and History. Cambridge University Press. V. 5, n. 3, p. 304-345, apr., 1963.

HAVELOCK, E.A. La musa aprende a escribir. Reflexiones sobre oralidad y escritura desde la Antigüedad hasta el presente. Trad. L. Bredlow. Barcelona: Paidós, 1996.

HORKHEIMER, M.; ADORNO, Th. Industria cultural como engaño de las masas. In: HORKHEIMER, M.; ADORNO. Dialéctica de la ilustración. Fragmentos filosóficos. Trad. J.J. Sánchez. Madrid: Trotta, 1994. p. 165-212.

KANT, I. Critica del juicio. Trad. M. García Morente. Madrid: Espasa-Calpe, 1999.

KOHLBERG, L. Psicología del desarrollo moral. Trad. M. A. Zubiaur. Bilbao: Desclée de Brouwer, 1992.

KROEBER, A.L.; KLUCKHOHN, C. Culture: A critical review of concepts and definitions. Cambridge: Harvard University Press. 1952.

MAYR, E. Animal species and evolution. Cambridge, MA: Harvard University Press, 1963.

Nueva Biblia Española. Trad. L. A. Shökel y J. Mateos. Madrid: Ediciones Cristiandad, 1993. 


$$
176 \text { - Remate de Males 35.1 }
$$

PIAGET, J. La psicología de la inteligencia. [1947]. Trad. J.C. Foix. Barcelona: Crítica, 1999.

PIAGET, J. Seis estudios de psicología. [1964]. Trad. N. Petit. Barcelona: Arial, 1990.

PLATÓN. Hipias Mayor. In: Diálogos. V. I. Trad. J. Calonge. Madrid: Gredos, 1981. p. 403441.

PLATÓN. Leyes. In: Diálogos. V. VIII. Trad, F. Lisi. Madrid: Gredos, 1999.

TYLOR, E. B. La ciencia de la cultura. In: KAHN, J. S. (comp.). El concepto de cultura. Barcelona: Anagrama, 1995. (Textos fundamentales).

WERTHEIMER, M. Über Gestalttheorie. [1924]. In: Gestalt Theory. V. 7, n. 2, Opladen: Westdeutscher Verlag, 1985. p. 99-120. 